\title{
ENSINO MÉDICO E PROMOÇÃo À SAÚdE EM CRECHE COMUNITÁRIA
}

*S. de A. Pinheiro, M.I.B.G. Moreira, M.A. de Freitas

TrabalhorealizadonoDepartamentodeMedicinaSocialdaFaculdadedeMedicinadoTriânguloMineiro,Uberaba,MG.

RESUMO - OBjETVOS. Apresentar a experiência de um trabalho comunitário em creche de 410 crianças, vinculada a uma instituiçăo católica e que se constitue em aulas práticas da disciplina Políticas de Saúde em curso de graduação em medicina.

Métodos. Através de conversa informal e brincadeiras, realizase observaçäo clínico-epidemiológica e levantamento de necessidades de saúde de crianças de três meses a seis anos.

RESULTADOS. Foram diagnosticados quatro temas relevantes para a clientela : higiene, saúde bucal, saúde ocular e dependência química em pessoas da familia. Para abordar essas questöes, organizou-se evento educativo interativo constituído de dramatização; gincana; filme e laboratório com peças anatômicas artificiais.

Conclusōes. Essas atividades proporcionaram oportunidade ao acadêmico de medicina de vivenciar uma realidade social até entäo pouco conhecida, e trabalhar sentimentos e compromisso com a saúde no nível coletivo.

UntreRMOS: EnsinoMédico.MedicinaSocial.AtençãoPrimária. Creches.
INTRODUÇÃO

O currículo do curso de graduação das escolas médicas brasileiras tem sido tema de amplos debates no sentido de atingir alguns objetivos urgentes, como $\mathrm{o}$ aumento das atividades práticas em proporção às teóricas, a capacidade de trabalhar em equipe, o compromisso social e a humanização do exercício profissional. Para tanto, muitos autores têm apresentado e discutido a incorporação de novos métodos pedagógicos, como a aprendizagem baseada em problemas, a diversificação de ambientes de treinamento', as dinâmicas de grupo e as estratégias mais abrangentes de reforma curricular com integração de conteúdose avaliação contínua do corpo docente.

*Correspondência:

Departamento de Medicina Social da FMTM Hospital Escola- Av Getúlio Guaritá s/n Bairro Abadia - Cep: 38040-450 - Uberaba

Tel.: (34) 3185222 ou 3185223 - Fax: $3333-8710$

E-mail: medsocial_fmtm@mednet.com.br
Apesar dos avanços jáatingidos por algumas escolas médicas no Brasil, fundamentadas na formação mais generalista de seus egressos, e inspirada em um modelo de saúde universalista e comprometido com uma maior equidade social, observa-se que o modelo flexneriano de ensino, voltado para especialidades ecentradona prestação deserviçoshospitalares, ainda predominae reproduz a disparidade entre a sofisticação tecnológica e os cuidados básicos de saúde de que carece a maior parte da população brasileira.

Nessa perspectiva "háuma concordância unânime sobre a excessiva tecnologização associada a desumanização do ato médico. Entretanto, a despeito desseponto de vista, todos encontram-se mergulhados nesses processos", como que contribuindo acontragosto paraacontinuidade do problema. Isso se aplica à análise do caso da medicina, onde se observa franca deterioração dos padrões éticos ${ }^{2}$.

NaFaculdade de Medicina do Triângulo Mineiro(FMTM), esse problemafoi debati- do entre corpo discente e docente, na tentativadeelaborarumareformacurricularque diminuísse o peso da carga horária teórica e aproximasse o ensino as reais necessidades da população assistida. Nessa escola médica, a disciplina de Políticas deSaúdefaz parte do curriculum de graduação médica desde 1994 e tem como objetivo geral proporcionar aos graduandos uma visão crítica do Sistema de Saúde no Brasil e das práticas em saúde $^{3,4,5}$. Para alcançar seus objetivos, desde sua implantação no curriculum, foram realizadasváriastentativas de atividades práticas que proporcionassem aos alunos uma visão abrangente e dinâmica do Sistema de Saúde em funcionamento no município de $U_{b e r a b a} 6$ e, embora muitos esforços tenham sido empreendidos, havia dificuldade de constituir um campo empírico para as atividades de campo.

Ao longo de alguns anos de atividades didáticas na disciplina, os alunos foram levados a visitar instituições municipais comoas Unidades Básicas de Saúde; estaduais, como a Diretoria Regional de Saúde e federais, 
como a Fundação Nacional de Saúde e as instâncias do INSS em funcionamento em nosso município. Também jáforam levados a conhecer o funcionamento de setores técnicos destinados a atividades específicas de Saúde Coletiva como, por exemplo, a estação de tratamento deáguas da cidade, 0 lixão municipal e outros setores da Secretaria Municipal de Saúde, tais como as Vigilâncias Epidemiológica, Sanitária e o Centro Médico queatua como unidade de referência secundária. Em 1997, iniciou-se um trabalho de reconhecimento de área em um bairro residencial periférico para realização de diagnóstico sócio-sanitário e ali foram realizadas visitas domiciliares, entrevistas individuais e coletivas e exames parasitológicos defezes, em crianças menores de 10 anos, cujos resultados foram divulgados através de uma atividade educativa em uma unidade da Secretaria Municipal de Ação Social, que então ofereceu à disciplina o espaço para reuniões com grupos de moradores.

Entretanto, essas atividades práticas caracterizaram-se por uma descontinuidade frustrantee antipedagógica. Muitas foramas razões para essa instabilidade, e dentreelas destaca-se a variação de interesse e compromisso de diversos órgãos de execução de serviços desaúde coma missão educativa da escola médica. Além disso, as próprias articulações interinstitucionais entre setor acadêmico, Prefeitura e suas secretarias ora aproximam, ora distanciam as instituições entre si, o que compromete uma atividade prática curricular estável e satisfatória emum campoempírico definido.

No ano de 1999, durante a discussão geral do ensino de graduação na FMTM, solicitou-se à área de Medicina Social o empreendimento de esforços nosentido de atingir objetivos gerais da formação do graduando quanto ao fortalecimento de seu compromisso social e sua capacitação para trabalhar emequipemultiprofissional, entre outros. Em seminário aberto a toda comunidade acadêmica, evidenciou-se, a partir dos próprios alunos, o interesse em vivenciar aspectos da área de Saúde Coletiva com mais atividades práticas. Esses elementos fortaleceram o intento de criação de novas áreas de atuação em saúde que se caracterizassem pela continuidade; por viabilizara observação do funcionamento atual do sistema de saúde e pela capacidade de envolver, responsabilizar eemocionar os alunos, fortalecendonelesvaloreséticos ehumanos profundamentenecessários paraa consolidação de seu compromisso com a saúde individual e coletiva para o futuro exercício profissional da Medicina.

Assimsendo,optou-seporreiniciaratividadesvoltadasà promoção de saúde dacomunidade deforma integrada ao sistema de saúde vigente, apartir de instituições quenãosofressem tãovisivelmenteainfluênciadas mudanças político-institucionais e que contassem com reconhecimentoelegitimidadepopularnomunicípio. Para conseguirviabilizar esseobjetivo, forameleitasasseguintesestratégias:

I.Estabelecer parceriacom Organizaçõesnão GovernamentaiscomprometidascomoSistema Único de Saúde e com a proposta de promoçãoaSaúdedaFamília.

2. Inserirocorpodiscenteematividadesdenível primário, realizadas na comunidade, comduraçãomínimadeoitosemanas, sobsupervisão diretadeum docentedaáreadeMedicinaSocial. 3. Realizar integração técnica e operacional, comosistemadesaúdemunicipal, particularmente como Programade SaúdedaFamília.

Doponto de vista didático-pedagógico, as atividades em comunidade deveriam contemplar os seguintes objetivos:

I. Promover a saúde da família na área de abrangência ${ }^{7,8}$

2. Sensibilizar o acadêmico de medicina e enfermagem paraa realidadesocial de população daárea ${ }^{9,10}$.

3. Desenvolver o conceito de cidadania e compromisso social.
4. Exercitaro trabalhoem equipecom membros daprópria comunidade.

5.Articular atividades universitáriasao Sistema Único de Saúde.

Entre as instituições do município que poderiamseralvo desta parceria, elegeu-se - Centro Comunitário São José Operário, anexo à paróquia de mesmo nome, conhecido e legitimado pela população por seu caráter de seriedade e utilidade pública. Nele são atendidas 450 crianças de zero a seis anos em uma creche.

Após contatos iniciais com a direção do Centro Comunitário, realizamos proposta de trabalho integrado na creche, que foi realizado no segundo semestre de $1999 \mathrm{e}$ primeiro semestre de 2000.

\section{Objetivo}

O objetivo desse texto é relatar uma experiência de ensino de promoção à saúde de crianças no Centro Comunitário a partir de atividades curriculares nas disciplina de Políticas de Saúde na Faculdadede Medicina do Triângulo Mineiro(FMTM).

\section{Métodos}

A população atendida pelo programa é clientela da creche do Centro Comunitário SãojoséOperário. Essainstituição de caráter filantrópico atende 410 crianças de três mesesa seis anos para permanência matutina e vespertina, enquanto suas mães encaminham-se e permanecem em seus locais de trabalho. Ospais e/ou responsáveis contribuem coma quantia de $R \$ 10,00$ (dez reais) por mês por criançaatendida eacrechecompleta seu orçamento comverbas de subvenção de instituiçãoprovedora católica.

Mantém, por convênio coma Prefeitura Municipal, um consultório comatendimento odontológico predominantementepreventivo, umaprofissional denível médio treinada para atendimento em saúde e uma sala instalada paraalgunsatendimentos de urgência 
e curativos pequenos. Quando necessário, encaminhaas crianças para serviços de unidades básicas do SUS e do Hospital Escola da FMTM. Fornece paraas crianças ali matriculadas, refeições, banho, instrução em nível de pré-escola, lazere educação básicaem geral.

As atividades a serem realizadas pelo programa foram discutidas com a diretoria da crechee seusfuncionários, pessoalmente, para estabelecer horários compatíveis entrea disciplina ea rotinas de trabalhocom as crianças. Ficou definido que inicialmente os acadêmicos realizariam pesagem, medição da estatura das crianças e observação clínica de condições de higiene e nutrição. Essa observação, entretanto, não seria realizada através de consulta médica e exame físico, uma vez que os acadêmicos ainda não passaram pelas disciplinas de Semiologiae Pediatria; seriafeita de forma informal, sem utilização de qualquer roteiro padronizado, duranteconversas ebrincadeiras. Cadaacadêmico deveria interagir com uma criança durante quarenta minutos a uma hora. Ao observar problemas de saúde, desenvolvimento psicomotor ou queixas relevantes da criança, os dados seriam anotados em uma ficha de atendimento individual com aidentificação da criança e um campo em aberto para descriçãolivre.

Ao longo de todo o processo, as ações desenvolvidasforam realizadas em conjunto com os funcionários da creche, com supervisão docente direta.

No primeiro dia, os alunos foram recebidos pela presidente da Creche, no saguão da igreja Sãojosé Operário; após sua exposição, compareceu também o responsável pelaparóquia, trazendoumavisão humanista do exercício damedicina.

No último dia, realizou-se um evento educativo nas dependências da creche, em quatro espaços diferentes. As crianças foram divididas em grupos de 50 elementose rodiziaram de forma a assistir e participar interativamente das atividades. Dentre as questões que as crianças abordaram nas conversas informais, foram selecionados os temas mais freqüentes, a saber:

I) Dramatização sobre alcoolismo. Os alunos escreveram, ensaiaram eapresentaram uma dramatização ao ar livre no parque da creche. Na primeira parte, o problema do abuso doálcool foi retratado em uma família, cujo paialcoólatraperdeu oemprego, tratava comviolência a mulher e os filhos, foi preso e, finalmente, manifestou o desejo de se tratar. Nasegundaparte, foram discutidos os caminhos de tratamentoerecuperação.Após a apresentação, ocorreu um debate comas crianças. Muitas delasapontaram comoúnico recurso de tratamento a freqüência a igreja católica ou evangélica. Osacadêmicos informaram-nas da existência de terapias oferecidaspelosistemadesaúdeeoutrasinstituições no município. Solicitaram que elas convidassem seus pais e/ou responsáveis a comparecerareuniões posteriores, quetratariam desse temanovamente.

2) Vídeo de saúde bucal: os acadêmicos produziram um vídeo com uma história ocorrida entre dentes saudáveis e dentes cariados. Enriquecerama trama comfundo musical próprio e comentários de um narrador que ia instruindo as crianças sobre prevenção, higiene e formação de cáries até a perda irreversível do dente doente. Destacaram os recursos odontológicose, ao final, realizaram debate com as crianças.

3) Teatro de fantoches sobre saúde ocular: uma história de dificuldade visual em um dos personagens foia estratégia paraseapresentar às crianças, através dos diálogos dos fantoches, questões como higiene, influência da acuidade visual no desempenhoescolar e recursos de saúde disponíveis no município para diagnósticoe tratamento.

4) Infecções respiratórias: Com exposição de peças anatômicas artificiais, cortes longitudinais da face, pulmões e traquéia de bor- racha foram apresentados às crianças para explicar o trajeto desecreções brônquicase de corpos estranhos. A seguir, as crianças queapresentavam corizareceberam lenços de papel e foram orientadas quanto à expiração, inspiraçãoe eliminação das secreções nasais como medida de higiene e de tratamento das vias aéreas superiores.

5) Gincana dehigiene: uma brincadeira estilo meninos contra meninas agitou a participação das crianças que enfrentavam o desafio de responder mais rápido as questões referentes a banho diário; pediculose; utilidade de pentes, escovas, sabonete e outros recursos de higiene pessoal.

Em uma das manhãs de trabalho, as atividades foramencerradas antes dachegada do ônibus para transportar a equipe de voltaà FMTM, e os acadêmicos, monitores edocentes foram convidados a almoçar na creche, no recinto da própria copa dos funcionários, com muita descontração ealegria. Aolongo das ações desenvolvidas, os acadêmicos e as crianças brincaram de roda, andaram de bicicleta, jogaram futebol, contarame ouviram estórias, cantaram e trocaram gestos de afeto.

Após o término das aulas, foram realizadas reuniões com os pais e responsáveis pelas crianças em horário de final de expediente, para relatar as ações desenvolvidas e discutir os temas levantados pelas crianças.

\section{RESULTADOS}

Oenvolvimento com essa comunidade possibilitou a discussão com funcionários, mães e crianças da creche sobre temas como pediculose, verminose, uso de drogas e doenças sexualmente transmissíveis. Do atendimento individual às criançasforam estabelecidosindicadores epidemiológicos paraa prevalência de desnutrição, observada e registrada em curva de desenvolvimento pôndero-estatural. 
As crianças de cinco e seis anos conversaram espontaneamente com os acadêmicos de medicina sobre violência doméstica e dependência química, muitas vezes referindo-se a pais e conhecidos moradores naárea de abrangência. Observou-se que as crianças tinham muito mais a dizer sobre essas questões do que os acadêmicos, que, não raro, limitavam-sea ouvir, às vezes tentando disfarçar sentimentos de espanto e indignação.

Mediantea identificação desses problemas, foram delineadas duas linhas de atuação: um trabalho educativo com as crianças ereuniões de discussão dos problemas com os pais e/ou responsáveis.

Oatendimento coletivo a pais e/ou responsáveis ocorreu em reuniões realizadas no salão da creche, contando com a presença de cerca de 100 pessoas, em cada reunião. Todo o trabalho desenvolvido com as crianças foi explicitado; as curvas de evolução pôndero-estatural foram entregues com as explicações metodológicas e encaminhamento para oserviço de pediatriapara aquelas com evidência de desnutrição. Temas como higiene, dependência química e violência doméstica foram abordados em forma de debate com participaçãoaberta de todos os presentes.

A partir dos depoimentos de criançase adultos usuários da crechee de moradores daquelaárea deabrangência, osacadêmicos perceberam aatuação das unidades básicas de saúde, da referência secundária e dos hospitais conveniados ao SUS que prestam atendimento àquela população.

\section{Comentários finais}

Durante o período letivo, nossa supervisão docente foi acrescentada por atendimentos eventuais a casos de pequenos acidentes, infecções respiratórias e outras questões de saúde trazidas tanto pelos acadêmicos quanto pela equipe de funcionários da creche. Todas as crianças foram matricu- ladas no ambulatório do hospital universitário e para lá encaminhadas paraatendimentos de maior complexidade em pediatria, psicologia ou clínica cirúrgica pediátrica.

Observou-se que alguns problemas de saúde na creche foram parcialmente abordados, embora ainda permanecessem sem solução definitiva. Por exemplo, as infes-tações por pediculose, em que algumas crianças adquirem no ambiente doméstico e outras na própria creche, refletem a necessidade de um trabalho educativo de higiene que deve continuar a ser feito periodicamente. O problema da desnutrição, observado em crianças novatas na creche, é sanado com o tempo de permanência, o que sugere o quanto a instituição supre necessidades básicas de famílias em condições precárias de subsistência. As cenas de violência, narradas pela fala das crianças, reflete um mundo diferente do cotidiano dos acadêmicos e propiciou, entre alguns, a oportunidade de relatar experiências pessoais e familiares de abandono, dependência química e preconceitos que foram sendo revistos após a atuação na creche.

O trabalho desenvolvido até o presente momento pareceu-nos adequado do ponto de vista didático-pedagógico para abordar de forma vivencial as diretrizes apontadas pelo MEC para formação geral do médico, como o fortalecimento de seu compromisso social, sua capacidade de trabalhar em equipe e de respeitar o saber popular em suas ações de educação em saúde. Pretendemos ir mais além, aprofundando nos conceitos de acolhimento a uma determinada demanda e no fortalecimento do vínculo com uma comunidade, no sentido de buscar, construir e conquistar condições concretas de saúde e direito à vida. Para tanto, parece-nos fundamental a continuidade do trabalho na creche, com observação semestral das crianças, manu- tenção das conversas informais e das reuniões periódicas com os pais e/ou responsáveis. Entretanto, pretendemos convidá-los para reunir em pequenos grupos, de no máximo 20 participantes, de acordo com a faixa etária de seus filhos, e, com o tempo, reorganizá-los por problemas específicos para que ocorra um aprofundamento das questões no estilo de grupos de ajuda mútua.

Odepoimento dos alunos, em avaliação oral realizadaao final da disciplina, eporescrito em texto livreexigido para seleção de monitores logo após o término das atividades, indicaqueessas conseguiram interferir no seu compromisso social e sensibilizá-los para o papel de médicos e de cidadãos.

\section{SUMMARY}

Medical teaching and HeAlth PROMOTION IN DAY NURSERY INSTITUTION

PURPOSE. The authors presenta communityworkexperience ina 410 children Catholicdaynurseryinstitution.

METHODS. Through non-structured interview and play, clinical-epidemiological observation and a survey of the health needs of three months to six years old children were made.

RESULTS. Fourrelevant themeswereidentifiedfor the population: hygiene, oral health, ocular health and substance abuse in some familymembers. In order to deal with these matters, an interactive educational program was organized whichincludedacting activities, films, competitions and laboratoryactivities withartificialanatomicshapes.

CONCLUSION. Theseactivitiesgivethemedicalstudent theopportunity togetacquainted with thenotvery well knownsocial realityand be committed to the publichealth.

[Rev Ass Med Brasil 200I ; 47(3): 320-4]

KEYwORDS: Medical Teaching. FamilyHealth. Preventive Medicine. Daynurseryinstitution. 


\section{REFERÊNCIAS}

I. Yazbeck DCM; Azevedo LL; Siqueira MRL; Menezes VM. Novos rumos para a educação médica. Rev Bras Educação Méd 2000; 24:26-30

2. Santana JP. O paradoxo da educação médica. Boletim ABEM 2000; 28:13-5.

3. Campos GWS. Subjetividade e administração de pessoal: considerações sobre modos de gerenciar trabalho em equipes de saúde. In: Mehrye, onocko R. Agir em saúde: um desafio para o público. São Paulo: Hucitec, 1997.
4. Ferreira SRS, Edit OR. Diagnóstico de saúde: uma experiência participativa da Unidade COINMA. Mom Perspec Saúde, 1996; 9:35-40.

5. Mello DA. Promoção à saúde e educação: diagnóstico de saneamento através da pesquisa participante articulada a educação popular (Distrito São João dos Queiroz, Quixadá, Ceará, Brasil). Cad Saúde Pública, 1998; 14:583-95.

6. Prefeitura Municipal de Uberaba. Uberaba em Dados, 1998.

7. Lecovitz E, Garrido NG. Saúde da família: a procura de um modelo anunciado. Cadernos Saúde da Família (Brasília); 1996:3-9.
8. Minas Gerais. Secretaria de Estado da Saúde. Programa de saúde da família: uma estratégia de mudança do modelo de saúde pessoas para implantação no município. Belo Horizonte, 1997. 45p.

9. Santos M. O espaço do cidadão. São Paulo: Nobel; 1996.

10. Vasconcelos EM. Educação popular e a atenção à saúde da família. São Paulo: Hucitec; 1999.

Artigo recebido: 19/10/2000 Aceito para publicação: 31/07/2001

\section{Arte Örasileira}

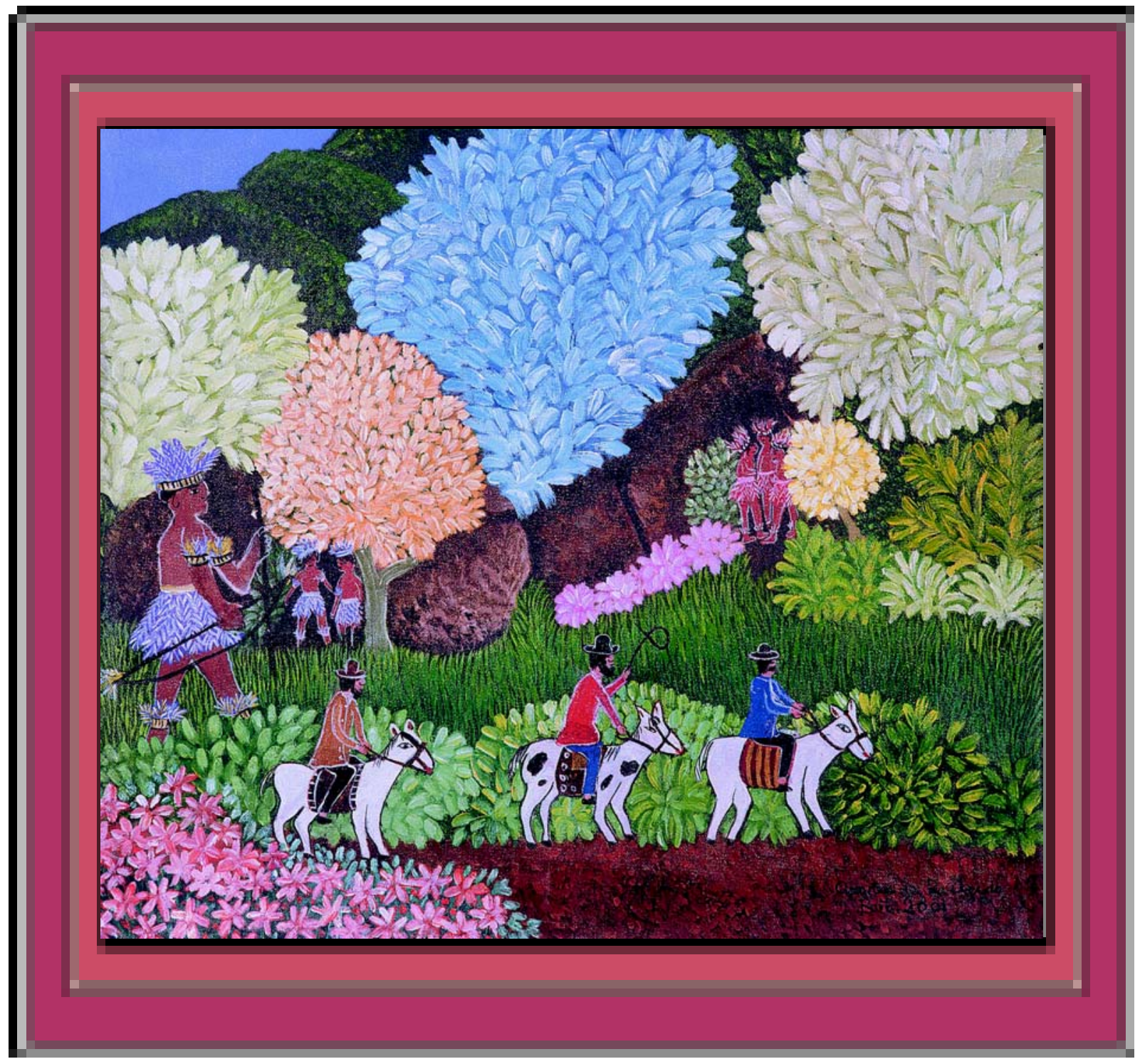

Aparecida Azedo - "Fugindo do Colonizador" -Galeria Jacques Ardies - Tel.: (II) 3884-2916 